\title{
O DESIGN GRÁFICO COMO FACILITADOR DA NOVA CULTURA DE CUIDADO E PROTAGONISMO NO ESPAÇO URBANO
}

Morgana Creuz

UNIVILLE - Universidade da Região de Joinville

morganacreuz.mc@gmail.com

Marli Teresinha Everling

UNIVILLE - Universidade da Região de Joinville

marli.everling@gmail.com

\begin{abstract}
Resumo: Este artigo descreve a experiência relacionada a pesquisa de mesmo nome, desenvolvida no Projeto de Pesquisa URBE ${ }^{1}$. Seu objetivo é a compreensão do estado da arte das temáticas que abrangem este cenário, bem como realizar um levantamento de ações que utilizam o design gráfico como meio de dinamizar as relações de uso do usuário com o espaço urbano. Para tal, empregou-se a pesquisa bibliográfica, por meio de consultas em diversas bases de dados e o estudo de caso aplicado, compreendendo a análise do cenário de três projetos. Osresultados obtidos serão aproveitados em atividades de pesquisa e capacitação que utilizam o design como ferramenta de transformação dos indivíduos e cidades, bem como contribuem para contextualizar o campo da experimentação da cidade.
\end{abstract}

Palavras-chave: Design gráfico, espaço urbano, cuidado, protagonismo

\begin{abstract}
This paper reports the related experience to the same name research, developed in the search project URBE2. The goal is to understand the state of themes that cover this scenario as well as conduct a survey of actions using graphic design as a means to streamline the user's use relations with the urban space. For this, was used the literature research, through consultations in various databases and the study of applied case, comprehending the analysis of three project's scenarios. The obtained results will be utilized in projects that use design as a tool for transformation of individuals and cities, as well as contributing to contextualize the experimentation field of the city.
\end{abstract}

Keywords: wanderings, urbanism, design

\footnotetext{
${ }^{1}$ Vinculado ao Laboratório de Estudos em Design-Cidade/LECid - Mestrado Profissional em Design da Univille.

${ }^{2}$ Bound to the Laboratory of Studies for Design-City/LECid - Professional Masters in Design Univille
} 


\section{INTRODUÇÃO}

Vive-se em uma cidade cada vez mais desordenada e sem vida. Trânsito, falta de espaços públicos de convivência e ambientes/espaços cada vez mais verticalizados, são alguns dos fatores que regem a sociedade desde a modernidade. Nos anos 60 as contradições deste modo de vida já se anunciavam em publicações como "Morte e Vida nas Grandes Cidades" redigido por Jane Jacobs, que já indicava as consequências do aumento de carros nas cidades e como tal tendência afetava negativamente o espaço urbano e à vida nas cidades. Durante boa parte do século XX, as cidades foram planejadas visando uma alternativa para melhorar o fluxo devido ao aumento contínuo do tráfego de automóveis, a limitação de espaços para as edificações e instalações das grandes empresas, ao invés de focar na dimensão humana. Segundo Jan Gehl urbanista e autor de várias publicações dentre as quais destaca-se 'Cidades para Pessoas' $^{3}$ (2015, p. 03), "a tradicional função do espaço da cidade como local de encontro e fórum social para os moradores foi reduzida, ameaçada ou progressivamente descartada".

Entretanto, observa-se o engajamento cada vez maior de pessoas, iniciativas públicas e privadas contra essa tendência apresentada e estabelecida ao longo do século XX. De acordo com Natalia Garcia (2013, web), jornalista, ativista e palestrante brasileira que dissemina conceitos relacionados a uma cidade mais humana por meio do projeto 'Cidade para Pessoas'3 é necessário despertar os quero (s), tenho (s) e posso (s), afim de melhorar a qualidade de vida das cidades. Ativando dessa forma, os quatro objetivos chave apontados por Gehl (2015, p.06): cidades e sua interface com vitalidade, segurança, sustentabilidade e saúde. Observa-se que, apesar de todos os desafios, muitas transformações estão acontecendo nas cidades em sincronia com tendências colaborativas, de empatia e mudança de cultura. Neste contexto, verificase a inserção de novos valores de consumo, em que a necessidade de diferenciação, a identidade regional, aliadas as referências globais culminam no resgate das raízes e métodos do passado na representação de um novo estilo de vida (STARLING; COSTA; PINNOW, 2015). Considera-se que parte da sociedade atual está levantando uma nova bandeira, e tomando o seu lugar como protagonista das cidades. Novas abordagens como a coletividade, o compartilhamento e o consumo consciente fazem parte deste discurso a favor da vida nas cidades. Neste movimento o cidadão é promovido a protagonista e agente transformador do meio em que vive, deixando seu papel de usuário passivo do espaço urbano (MANZINI, 2014).

Diante desse contexto, o objetivo desta pesquisa é realizar um levantamento sobre as possibilidades de uso do design gráfico como meio de dinamizar as relações de uso do usuário com a cidade e sensibilizar para o papel da cidadania, do coletivo e do cuidado. A metodologia utilizada é baseada na pesquisa bibliográfica e estudo de caso aplicado, em que analisou-se as ações: Que ônibus passa aqui?; Walk your City; e Mapa Daqui, visto que são movimentos a favor das cidades que buscam dar voz aos cidadãos, por meio de múltiplas plataformas. Tais ações foram escolhidas, tomando como base as informações compartilhadas em um grupo fechado do Projeto de Pesquisa em uma mídia social, que tem como objetivo a disseminação de boas práticas e utilização do design nas cidades. Percebeu-se que por meio de ações simples, estes movimentos estão transformando o cotidiano das pessoas, promovendo engajamento 
e gerando impactos positivos na sociedade em que atuam. Contribuindo assim para o desenvolvimento de uma cultura de cuidado com a cidade.

Este artigo foi estruturado visando a compreensão temática projetual e posteriormente elaborou-se a análise das ações destacadas anteriormente, por meio das bases teóricas defendidas por: Gehl (2015), Jacobs (2011), Lynch (2011), Garcia (web) e Manzini (2014) no campo do espaço urbano; Fraser e Banks (2007), White (2006), Ambrose e Harris (2009), IDEO - HCD (2013), Sanders (2002), Lupton (2013) e Vianna et al. (2012) no que tange técnicas de design gráfico e relações de uso.

\section{DESENVOLVIMENTO}

O estado da arte/técnica das temáticas relacionadas a cidade para pessoas, design gráfico e relações de uso no contexto urbano visa fundamentar a análise posterior de ações reais com foco no design gráfico, colaboração, protagonismo e cuidado com a cidade. Baseado neste contexto, a abordagem inicial é sobre cidade para pessoas, temática esta já consolidada em alguns países europeus, que revoluciona o modo de ver e viver o espaço urbano.

\subsection{Cidade para pessoas}

Pouco disseminada na sociedade, a temática cidade para pessoas, já vem sendo estudada há pelo menos cinquenta anos ao redor do mundo. Em um momento em que as cidades evoluíam, o tráfego automotivo aumentava e a população crescia, ocorreu um despertar em alguns arquitetos e urbanistas, dentre eles Jan Gehl, a respeito da forma e vida nas cidades. Em conversas com sua esposa, a psicóloga Ingrid Gehl, o arquiteto percebeu a importância de conceber a dimensão humana em seus projetos (GEHL, 2015). Outros pesquisadores também embasaram seus estudos nesta tendência, como Jane Jacobs, Kevin Lynch. A grande diferença está no modo como os planejadores urbanos observaram estas constatações e incluíram tais delineamentos em seus planejamentos urbanísticos.

O caos vivenciado atualmente em algumas cidades, poderia ter sido evitado caso planejamentos com foco nas pessoas tivessem sido executados ao longo das décadas. De acordo com a revista The Economist (CASTRO, web) São Paulo é a cidade que mais cresce em competitividade a nível mundial. Entretanto, pesquisas realizadas pela OMS - Organização Mundial da Saúde (apud CASTRO, 2012, web) afirmam que a capital paulista possui o maior número de casos de transtornos mentais no mundo. Garcia (2013, web) reflete sobre essa questão afirmando que "as réguas que medem a cidade estão velhas, não [dando] conta da diversidade das pessoas".

Percebe-se que todo esse avanço está comprometendo a saúde das cidades e pessoas que nelas vivem. As enchentes, por exemplo, são consequências dos planejamentos fracassados de arquitetos, urbanistas e engenheiros que canalizam e concretam os rios para contribuir com o avanço das cidades. De acordo com Garcia (2013, web) São Paulo é uma das cidades do mundo que mais possui rios, entretanto poucas são as pessoas que possuem esse repertório, visto que a maioria, está escondido pelo asfalto. Construída sobre complexas áreas de mangue, Joinville enfrenta obstáculos semelhantes, visto que as enchentes na cidade são constantes (ANDRIGHI; BARROS, 2015). Mueller (et al. 2012, p. 24) afirma que em muitas cidades brasileiras, "a ausência de um planejamento territorial efetivo e comprometido com a realidade e a fragilidade ambiental na qual se insere" contribuiu para que Joinville se 
expandisse desordenadamente inclusive em locais não apropriados. Nestas circunstâncias, as medidas para evitar os congestionamentos também são tomadas visando a única resposta certa: o alargamento e a criação de avenidas. Entretanto, pesquisas comprovam que os carros não levam a maioria das pessoas, mas sim ocupam a maioria do espaço. Para Peñalosa (apud GARCIA, 2013 web) "resolver o trânsito construindo mais avenidas é como apagar o fogo com gasolina".

Paralelamente, observa-se o aumento significativo da população em áreas urbanas. Segundo dados quantificados pelo Censo (IBGE - Instituto Brasileiro de Geografia e Estatística 2010, web) cerca de 84\% da população brasileira mora nos centros urbanos. Esses dados indicam um investimento cada vez maior em infraestrutura urbana. Entretanto, vale ressaltar que esses esforços devem buscar respostas invisíveis. Garcia (2013, web) destaca que é mais cômodo persistir no erro do que propor projetos que maximizem as características das cidades. Ou seja, se falta espaço para os carros é mais fácil construir mais avenidas do que investir em transporte público, ativo de qualidade. Gehl (2015) em sincronia com Garcia (2013, web) afirma que "um maior número de vias convida ao tráfego de automóveis. Melhores condições para os ciclistas, convidam mais pessoas para pedalar. Ao melhorar as condições para os pedestres, não só reforçamos a circulação a pé, mas também - e mais importante - reforçamos a vida da cidade" (GEHL 2015, p.19).

Construir uma cidade com foco nas pessoas demanda tempo, comprometimento e muito planejamento. Transformar uma cidade com foco na velocidade, no ganho de tempo para veículos motorizados e que visualiza no concreto, a única forma para ampliar a entrega de todos estes itens, exige muito mais, a começar por uma mudança de cultura dos indivíduos e da própria cidade. Dessa forma, por meio de pequenas ações pode-se elaborar com a participação da sociedade possibilidades para melhorar o cotidiano, fazendo da colaboratividade uma estratégia para repensar a atitude e a vida das cidades. O design passa assim a ser considerado como estratégia de uma nova cultura que vem ganhando cada vez mais adeptos e está em sincronia com discussões do Professor, escritor e Designer Ezio Manzini (2014) em palestra proferida no 110 Congresso Brasileiro de Pesquisa e Desenvolvimento em Design; nesta ocasião situou o desafio do design em um mundo em transformação em ações relacionadas ao projeto de aspirações, artefatos e sistemas menos voltados para um consumo potencializando, por outro lado, oportunidades relacionados a riqueza de ecossistemas naturais e sócio-tecnológicos assim como, bens de relacionamento (fundamentados na colaboração, compartilhamento, cuidado, troca de conhecimento, co-criação favorecendo a concepção coletiva o comprometimento e o engajamento).

Compreender as possibilidades do design gráfico como ferramenta de colaboração e cuidado com a cidade, é possível considerando as inúmeras contribuições da área para com o espaço urbano. Da mesma forma, analisar as relações de uso entre pessoas e produtos, serviços e ambiente em que estão inseridos possibilita compreender como projetar experiências positivas e diferenciadas aos indivíduos/coletividade, incluindo a abordagem de conceitos relacionados ao design gráfico e relações de uso no contexto urbano.

\subsection{Design gráfico e relações de uso no contexto urbano}

O design compreende uma grande e complexa área de atuação. Sendo três os principais influenciadores que contribuíram para sua expansão, segundo Cardoso 
(2008): a industrialização, a urbanização moderna e a globalização. Dessa forma diferentes ramificações do design surgiram a fim de suprir as demandas criadas por cada um deles. Assim o "design gráfico é um processo técnico e criativo que utiliza imagens e textos para comunicar mensagens, ideias e conceitos, com objetivos comerciais ou de cunho social" (ADG BRASIL, 2015, web). Muitas vezes as áreas do design gráfico e das artes são confundidas; para Fuentes (2006, p. 23), entretanto o diferencial está no atributo informacional inerente ao design.

Fuentes (2006) afirma que o principal suporte do design gráfico é o papel. Entretanto considerando o contexto em que este está inserido, observa-se possibilidades de contribuição da área para a nova cultura de cuidado com as cidades. Para o autor "o contexto de trabalho do designer é o mundo, tanto o ambiente físico primário como a complexa trama formada pela cultura humana, sem esquecer o determinante entorno emocional, pessoal e intransferível, de quem desenha" (IBID, 2006, p. 121). Observa-se a utilização das cidades como suporte em diferentes aspectos: o tradicional, como por exemplo a sinalização, ou ainda a experimentação, incluindo as intervenções urbanas. No decorrer desta pesquisa serão analisados os conceitos e resultados que tangem tais aspectos, em que o design gráfico é um facilitador dessa nova cultura.

A abordagem do design muitas vezes é contemplada apenas por sua forma física. Entretanto, sua função e relações de uso devem ser consideradas desde o primeiro esboço de projeto. Lupton (2013, p.04) afirma que "o processo de design é uma mistura de ações intuitivas e intencionais", desenvolvidas visando a satisfação e interação entre os usuários e os produtos/serviços elaborados. Dessa forma considerase que há "um amplo campo de ação por parte do design e de áreas afins, que podem trabalhar ações e soluções para as necessidades emergentes das cidades, contribuindo para a construção de cidades mais sustentáveis" (EVERLING, et al., 2014, p.04). Reforçando a proposta de interação e colaboração, Smith (apud LUPTON, 2013, p.06) afirma que "o processo de design, em sua melhor faceta, integra as aspirações da arte, da ciência e da cultura". Com base nas temáticas analisadas, será iniciado o estudo das ações com foco no design gráfico.

\subsection{Análise de ações com foco no design gráfico}

Os casos analisados foram escolhidos com base no impacto provocado onde estão inseridos. São experiências que tem no design gráfico o fundamento para comunicação, disseminação de ideias e protagonismo dos indivíduos. Serão analisadas as intervenções: Que ônibus passa aqui?, Walk your City e Mapa Daqui (Figura 01). 


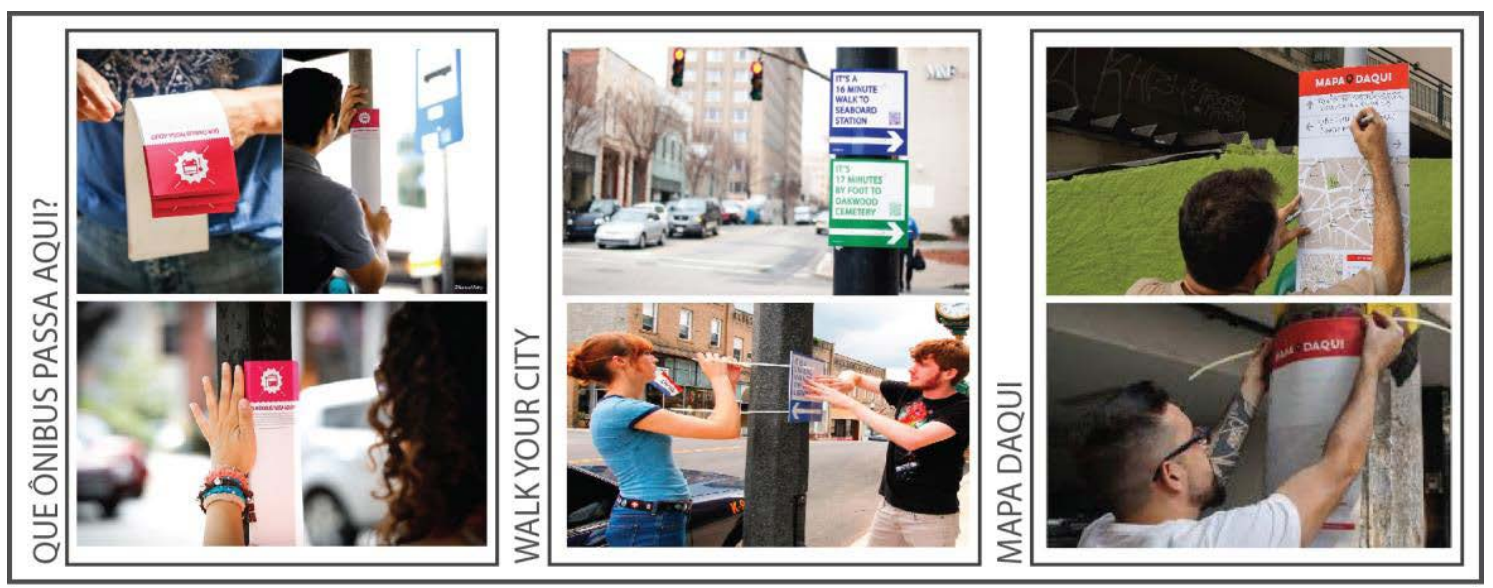

Figura 1 - Ações analisadas

Fonte: Elaborado pelo autor, com base na pesquisa realizada

\subsubsection{Contextualização das ações}

Inicia-se a contextualização das ações, com o projeto do estúdio criativo Shoot the Shit, de Porto Alegre (RS): 'Que ônibus passa aqui?'. A criação do estúdio deu-se quando um grupo de amigos publicitários, Luciano Braga, Gabriel Gomes e Giovani Groff, decidiu investir em soluções para problemas da cidade. Juntos eles formaram o estúdio criativo Shoot the Shit (em tradução livre significa: trocar ideias), de acordo com o site do projeto (web) a proposta é idealizar "projetos criativos para comunicar causas de organizações, mobilizar pessoas para ação e deixar um legado positivo para a cidade". As ações do grupo são baseadas nos pilares da criatividade e do protagonismo dos indivíduos. Criada em 2012, a ação 'Que ônibus passa aqui' foi uma das primeiras intervenções realizada pelo grupo. Os criadores (2012, web) afirmam que "é mais fácil cada pessoa cuidar do ponto de ônibus mais próximo de sua casa do que a prefeitura cuidar de todos os pontos da cidade". A proposta do grupo foi dividir as responsabilidades, mostrando que com pequenas contribuições, os cidadãos podem melhorar o contexto da cidade em que vivem.

A articulação desta iniciativa com os conceitos de Gehl (2015), Jacobs (2011) e outros pesquisadores de cidade para pessoas é evidente. No momento em que os indivíduos percebem a cidade e passam a interferir e viver ela, muitos dos desafios são resolvidos e a dinâmica do espaço urbano é mais efetiva. O design gráfico é utilizado como ferramenta da intervenção e percebe-se uma preocupação com a criação do material impresso e digital no que tange ergonomia visual, materiais e processos gráficos, cores, tipografia, entre outros elementos.

A proposta desta instalação tem na rua o seu local de exposição, utilizando-a como suporte para a crítica pela falta de investimento na melhoria física e informacional dos pontos de ônibus, seja por parte do poder público ou por empresas de transporte coletivo, tendo como linguagem básica o bom humor. A instalação utiliza dos espaços públicos, especificamente os pontos de ônibus, para propagação de sua mensagem, que é divulgada por meio dos stickers. Este formato de comunicação estimula a colaboração, tendência da contemporaneidade, e resulta em ganhos valiosos para todos os usuários de transporte coletivo, como por exemplo o tempo. A proposta foi iniciada em Porto Alegre, entretanto atualmente atinge cerca de 30 cidades, inclusive fora do Brasil. O que possibilitou tal abrangência é a disponibilização 
gratuita de seus meios de relacionamento, arquivos digitais das peças gráficas e as instruções, para que mais pessoas e cidades participem do movimento e se engajem como multiplicadoras do movimento. Ressalta-se que o coletivo estimula estes novos agentes transformadores a registrar as ações em fotos e vídeos e compartilha-las com o grupo suas intervenções contagiando mais pessoas a fazer a diferença, experenciando e melhorando a sua cidade.

A segunda ação analisada, Walk your City surgiu em 2012, na cidade de Raleigh, nos EUA. Um grupo de pessoas imergiu na cidade, desfrutando dela por meio do caminhar; a ideia era convidar as pessoas a realizar parte de seus trajetos por meio deste modal, que é o mais antigo e o mais acessível a maioria da população, mas que está sendo esquecido, visto o protagonismo dos veículos motorizados. O grupo espalhou placas, sinalizando o tempo necessário para chegar em locais considerados importantes na cidade, visando a conscientização das pessoas sobre a importância de elas ocuparem o espaço urbano a pé. A metodologia adotada pelo movimento foi nomeada de guerrilla wayfinding, ou seja, desbravar a cidade por meio de ações de guerrilha. Ressalta-se que na cidade em que o movimento foi iniciado, a instalação destas placas se tornou política permanente do município (WALK YOUR CITY, web; NOGUEIRA, 2013, web; ZOTTIS, 2014, web).

Percebe-se o real embasamento das atividades do grupo em autores com teoria fundamentada na temática cidade para pessoas, dos quais destaca-se Lynch (2011) que discute, entre outros conceitos, o entorno do local em que os indivíduos estabelecem seu cotidiano. Além de Jacobs (2011) que considera a recuperação da vitalidade da rua como critério base de seus estudos, visto que é na rua que o indivíduo aprende como se socializar e conviver. O grupo utiliza diversos princípios apresentados por eles sobre a ocupação das pessoas no espaço urbano, visando uma cidade mais viva, segura, sustentável e saudável. A ferramenta escolhida para intervenção na cidade é o design gráfico; observa-se que os criadores do projeto se empoderaram das técnicas de sinalização, no que tange ergonomia visual, materiais e processos gráficos, além do estudo de cores e tipografia. O material desenvolvido possui forte impacto visual, com um layout simples e fácil de entender.

A proposta do Walk your City é que este movimento se espalhe pelo mundo, convidando outras pessoas ou coletivos a serem protagonistas de suas cidades. Os materiais são disponibilizados digitalmente por meio do site do movimento, bem como as instruções de desenvolvimento gráfico, impressão e instalação. Ao término, os agentes de transformação são convidados a compartilhar suas ações, criando uma rede de boas práticas nas cidades do mundo.

Percebe-se que diversos coletivos, grupos e pessoas vêm se apropriando da proposta Walk your City e utilizando a proposta para transformar a sua região. Em Joinville (SC), o coletivo Diverte Inverte se sensibilizou com a ideia e, espalhou pela cidade diversas placas convidando as pessoas a caminhar pela cidade. A ação foi pontual e aconteceu em junho de 2014; em entrevista para o Jornal Notícias do Dia (NUNES, 2014, web) o coletivo afirma que "essas ações são importantes porque é fácil cair na rotina do dia a dia e esquecer o que realmente importa para a nossa vida e para a sociedade". Joinville foi a segunda cidade do Brasil a receber a intervenção; anteriormente o coletivo Shoot the Shit, já havia se apropriado da ideia e espalhado as placas na cidade de Porto Alegre (RS). De acordo com a página do coletivo em uma mídia social (2016, web) "seja pelo lado cultural, de viver e experienciar os detalhes da 
cidade ao nível dos olhos, seja pela questão da segurança, mais pessoas na rua tornam o ambiente mais seguro, seja pela busca de práticas mais sustentáveis de mobilidade".

A terceira ação é o Mapa Daqui. Inspirado em ações de Londres, em que o pedestre acessa por meio de totens, informações sobre pontos de interesse em um raio de aproximadamente 5 a 15 minutos de caminhada, Lucas Neumann criou o Mapa Daqui. Desenvolvido no ano de 2015 atualmente está presente de forma viva, nas ruas de São Paulo (RUSSO, 2016, web). O movimento estimula os cidadãos a conhecer sua região, via ações colaborativas. Segundo Montagner (2015, web) "mapas de qualquer região da cidade são disponibilizados em um formato pronto para imprimir e espalhar por aí. Uma vez que o mapa está na rua, qualquer pessoa com uma caneta pode sugerir um local próximo e indicar as direções para quem passar por ali depois".

$O$ contexto de cidade para pessoas é percebido também nesta ação que utiliza os conhecimentos em design gráfico para fazer dos cidadãos agentes de transformação de sua cidade. As cores, tipografia, formato, suporte, fixação e ergonomia visual são aspectos fundamentais da ativação impressão do projeto. Também se percebe o design gráfico inserido nas etapas digitais do projeto, a preocupação com a usabilidade e a experiência do usuário são fatores visíveis no site e mídias sociais do movimento.

De acordo com Russo (2016, web) o projeto já conquistou adeptos em quinze estados brasileiros, sendo assim o protagonismo por meio da ação é visível e comprovada por meio do compartilhamento de imagens. Ainda de acordo com o jornalista "a falta de sinalização para pedestres é um problema enfrentado por muitas outras cidades, que podem se tirar proveito da iniciativa espalhando por suas ruas indicações de pedestres para pedestres".

Os impactos destas ações são vivenciados nos campos social e visual, visto que se aplica tanto por seu contexto e mensagem, quanto por sua aplicação e resultados obtidos nas diferentes cidades. Ressalta-se que com o cidadão atuando como agente de transformação das cidades, os problemas destes espaços diminuem, ou ainda deixam de ser percebidos. Dessa forma, acredita-se que tais ações cumprem seu papel de mobilização social. Na sequência será apresentada a análise visual das ações, no que tange a aplicação dos fundamentos de design gráfico nos projetos.

\subsubsection{O design gráfico como ferramenta das ações}

Sabe-se que o design é uma área do conhecimento que visa o desenvolvimento de projetos com foco na melhoria contínua da interface dos indivíduos com o espaço em que vivem. Por sua vez, o design gráfico segundo Frascara (2000) contribui com a melhoria da qualidade de vida, visto que seus fundamentos estão conectados as possibilidades de enfrentar problemas sociais devido a conexão com o conceito de desenvolvimento sustentável. No que refere a metodologia projetual aplicada para desenvolvimento das ações, percebe-se que ambas estão conectadas com o design thinking ${ }^{4}$. Em linhas gerais, os projetos inicialmente partem da imersão, aproximandose do contexto problema, na sequência os insights são organizados para compreensão do problema visando iniciar a fase de ideação, com a geração de alternativas e prototipação para análise da viabilidade do projeto (VIANNA, et al. 2012).

Observando os conceitos de composição da imagem, percebe-se uma preocupação funcional e estética com os materiais impressos e digitais de ambas as

\footnotetext{
${ }^{4}$ Fundamenta-se com base em Vianna et al. (2012).
} 
ações. Independentemente do suporte escolhido para desenvolvimento das ações nas cidades: stickers (adesivos), placas rígidas de PVC (policloreto de vinil), banners de lona flexível ou ainda papel, popularmente conhecidos como lambe-lambe, a riqueza visual e a usabilidade são perceptíveis. A paleta de cores frequentemente é composta pela combinação de cores vibrantes mescladas com neutras. Segundo Fraser e Banks (2007) este tipo de aplicação cromática auxilia na leitura devido ao contraste gerado, influenciando positivamente no impacto visual despertado. A ação 'Que ônibus passa aqui' utiliza a composição azul e rosa, no que tange a combinação intensa aliadas a neutralidade do cinza e branco. No projeto Walk your City, é determinada uma cor vibrante, dependendo do ponto de interesse anunciado: roxo, para pontos comerciais; laranja, para locais de diversão; azul, para locais cívicos ou institucionais e; verde, para espaços públicos, juntamente com a base em braço. Já no Mapa Daqui as cores predominantes são o vermelho, o cinza e o branco. A tipografia empregada em todas as ações é sem serifa, facilitando a leitura e atribuindo uma estética arrojada e informal aos materiais. White (2006) afirma que a escolha da fonte afeta o caráter e a personalidade do material que está sendo desenvolvido.

O formato dos materiais diferencia-se conforme o conteúdo, garantindo uma boa aplicação e destaque. Ambrose e Harris (2009, p.09) definem que "a seleção do formato depende de considerações práticas como o público alvo, a natureza das informações a serem apresentadas e os custos envolvidos". O material, mesmo com suas múltiplas opções são em sua maioria duráveis e fáceis de aplicar. Observa-se que tais características contemplam os requisitos de materiais desenvolvidos para ambientes externos, de grande circulação e constantemente influenciados pelas ações climáticas. Todos os materiais das ações analisadas são, peças de sinalização, visto que eles auxiliam os passantes a se locomover mais efetivamente. Lynch (2011) aborda os conceitos de bem-estar e equilíbrio ao vislumbrar o momento em que os cidadãos sabem para onde vão ou como chegar a um destino. Entretanto, no contrário, a frustação, a falta de segurança e o medo se fazem presentes. "Portanto, uma imagem clara do entorno constitui uma base valiosa para o desenvolvimento individual" (LYNCH, 2011 p. 05).

A figura 02 apresenta uma compilação de aspectos destacados nas análises, correlacionando as diversas ações com a utilização do design como ferramenta de cuidado com a cidade e protagonismo dos indivíduos neste contexto. 


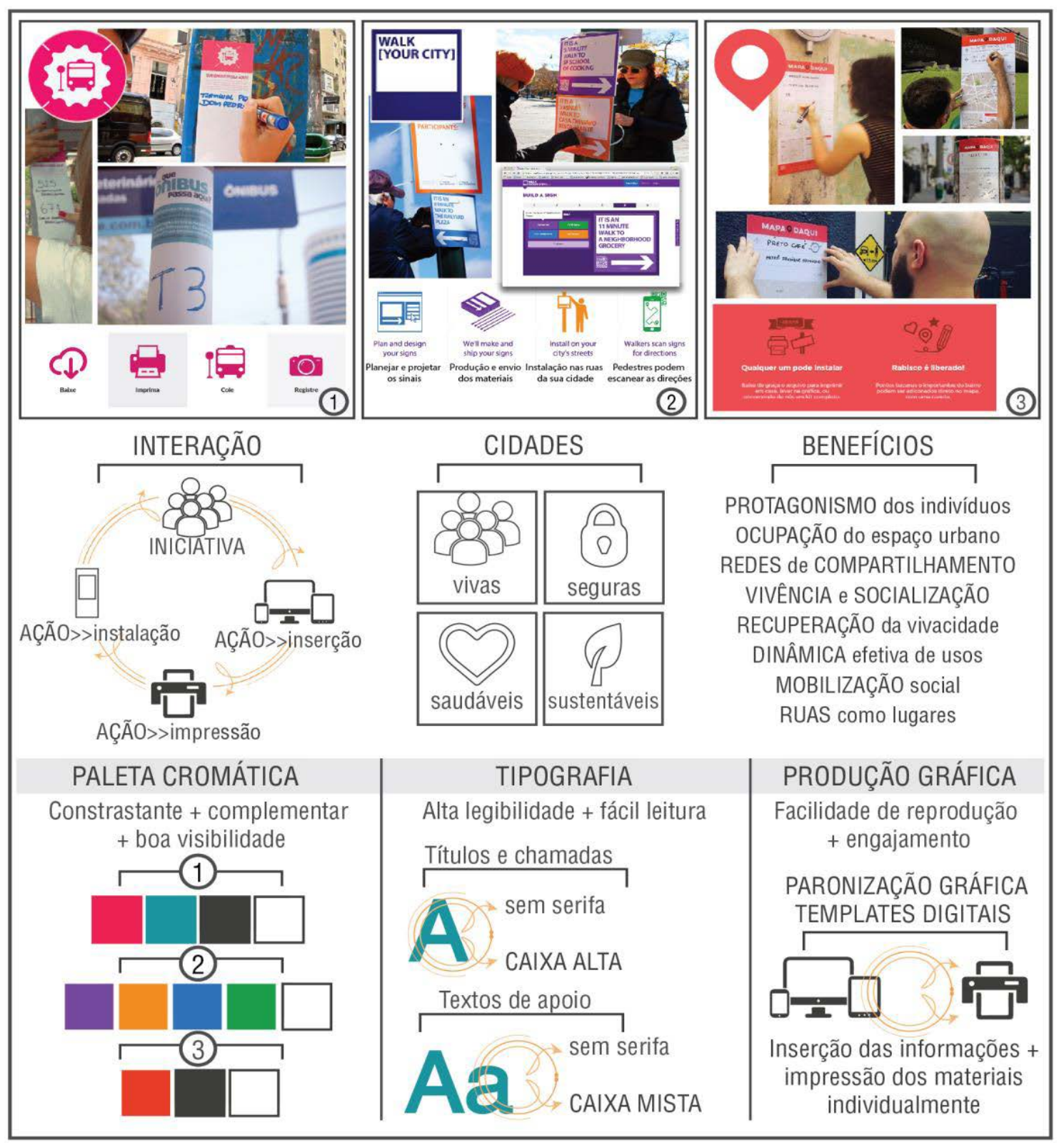

Figura 2 - Infográfico das ações analisadas

Fonte: Elaborado pelo autor, com base na pesquisa realizada

\section{CONCLUSÃO}

Percebe-se que as redes sociais e mídias digitais, associadas ao design gráfico, tem potencial para o engajamento dos cidadãos para com a resolução de desafios do espaço urbano. Em evento realizado em 27 de abril de 2016, sobre a temática cidades e sustentabilidade, promovido pelo PPGDesign Univille, o Prof. Dr. Luiz Vidal Gomes afirma que projetos pequenos criam uma nova atmosfera e estimulam mais pessoas a vivenciar as cidades. Novas possibilidades e usos para espaços até então despercebidos, possibilitam um novo olhar e despertam o cuidado e o pertencimento naqueles que colaboraram com a iniciativa. Ferramentas são necessárias para driblar tais situações; dessa forma tem-se no design um instrumento de interação, transformação e multiplicação. A análise realizada focou em ações desenvolvidas no território nacional; entretanto, visto a inspiração internacional de alguns projetos, 
verifica-se que esta tendência está encontrando adeptos em todo o mundo. No mesmo evento citado o Geógrafo e Professor Msc. Naum Santana reflete sobre o estilo de vida contemporâneo, que prioriza o viver fora de casa, estabelecendo uma nova necessidade e um novo padrão, que prioriza a qualidade nas ruas e nos espaços urbanos.

Os resultados e as percepções vivenciadas durante o desenvolvimento desta pesquisa serão úteis para as atividades em andamento e outras, ainda, no campo das ideias. A parceria com o Instituto Caranguejo de Educação Ambiental ${ }^{5}$, vem oportunizando a experimentação do design gráfico direcionado para empreendimentos sociais, contribuindo para a valorização e o consequente cuidado do mangue de Joinville e suas áreas/comunidades de entorno. Ainda nesse sentido, em aproximação com a Fundação Instituto de Pesquisa e Planejamento para o Desenvolvimento Sustentável de Joinville (IPPUJ), está sendo desenvolvido um sistema integrado para o transporte da cidade, com foco no uso das bicicletas, utilizando competências do design de serviços/gráfico para desenvolvimento projetual. Além das iniciativas citadas, os resultados e percepções desta pesquisa trarão benefícios a novas pesquisas do Grupo de Pesquisa Urbe e Laboratório de Estudos da Cidade (LECid) abrindo horizontes para a continuidade da análise de outras ações desenvolvidas.

Perceber o design gráfico como ferramenta para fomentar a cultura de cuidado, da participação e do protagonismo nas cidades possibilitou o reconhecimento de outro campo de aplicação destes conhecimentos. Em uma sociedade que visa o lucro e costuma não olhar para o seu entorno, o design pode contribuir para com este despertar dos cidadãos; ao mesmo tempo, a cidade e o espaço público passam a constituir também em oportunidade profissional/social.

\footnotetext{
${ }^{5}$ Organização da Sociedade Civil de Interesse Público cujo objetivo é "promover a Educação Ambiental nas Escolas e nas Comunidades" (INSTITUTO CARANGUEJO DE EDUCAÇÃO AMBIENTAL, web).
} 


\section{REFERÊNCIAS}

ADG BRASIL, $O$ valor do design: guia ADG Brasil de prática profissional do designer gráfico. São Paulo: 2 ed. Editora SENAC, 2004.

ADG BRASIL. Apresentação. Disponível em <http://www.adg.org.br/institucional/apresentacao>. Acesso em: 25 abr. 2015.

AMBROSE, Gavin; HARRIS, Paul. Fundamentos de design criativo. Porto Alegre: Bookman, 2009.

ANDRIGHI, Jean Fabyano; BARROS, Virgínia Grace. Cenários para o desenvolvimento de uma sinalização de trânsito voltada ao projeto Rota Segura, no município de Joinville (SC). In: MORGENSERN, Elenir; AGUIAR, Victor (Org.). Cenários culturais e sociais do design. Joinville: Editora Univille, 2015, p. 139-157.

BONSIEPE, Gui. Design, cultura e sociedade. São Paulo: Blucher, 2011.

CARDOSO, Rafael. Uma introdução à história do design. 3 ed. São Paulo: Edgar Blücher, 2008.

CASTRO, Fábio. Grande São Paulo tem alta prevalência de transtornos mentais.

Disponível em: http://agencia.fapesp.br/grande_sao_paulo_tem_alta_prevalencia_de _transtornos_mentais/15215/>. Acesso em: 25 abr. 2015.

EVERLING, Marli Teresinha, et all. A educação e seu papel mobilizador para o design. In: CONGRESSO BRASILEIRO DE PESQUISA E DESENVOLVIMENTO EM DESIGN. 11, 2014. Gramado - RS. Disponível em: <http://www.ufrgs.br/ped2014/trabalhos/ trabalhos/933_arq2.pdf>. Acesso em: 02 maio 2015.

FRASER, Tom; BANKS, Adam. O guia completo da cor. São Paulo (SP): SENAC/SP, 2007. FUENTES, Rodolfo. A Prática do Design Gráfico - Uma Metodologia Criativa. São Paulo: Rosari, 2006.

GARCIA, Natália. Cidade para pessoas. Disponível em:

<http://www.cidadeparapessoas.com.br>. Acesso em: 11 abr. 2015.

GARCIA, Natália. Cidades para pessoas: Natalia Garcia no TEDxFloripa 2013.

Disponível em: <http://www.youtube.com/watch?v=GNaovn4ta7M>. Acesso em: 11 abr. 2015.

GEHL, Jan. Cidades para pessoas. São Paulo: Perspectiva, 2015.

IBGE. Censo 2010: população do Brasil é de 190.732.694 pessoas. Disponível em: $<$ http://saladeimprensa.ibge.gov.br/noticias?view=noticia\&id=1\&busca=1\&idnoticia $=1$ 766> Acesso em: 24 abr. 2015.

INSTITUTO CARANGUEJO DE EDUCAÇÃO AMBIENTAL. Disponível em <http://www.caranguejo.org.br>. Acesso em 25 de maio de 2016

JACOBS, Jane. Morte e Vida de Grandes Cidades. Tradução de Carlos S. Mendes Rosa. 3 ed. São Paulo: WMF Martins Fontes, 2011.

LYNCH, Kevin. A imagem da cidade. São Paulo: Editora WMF Martins Fontes, 2011.

MAPA DAQUI. Disponível em:

<https://www.facebook.com/projetomapadaqui/timeline>. Acesso em: 04 maio 2016. 
MAPA DAQUI. Disponível em: <http://mapadaqui.org/>. Acesso em: 04 maio 2016.

MONTAGNER, Camila. Um mapa na rua, e pedestres dizem a pedestres o que há de melhor por aí. Disponível em: <http://outracidade.com.br/um-mapa-na-rua-e-pedestresdizem-pedestres-o-que-ha-de-melhor-por-ai/>. Acesso em: 04 maio 2016.

NOGUEIRA, Pedro Ribeiro. Coletivo incentiva ação e mostra que cidade se faz ao caminhar. Disponível em: <http://portal.aprendiz.uol.com.br/2013/10/22/plataformamostra-que-a-cidade-se-faz-ao-caminhar/>. Acesso em: 04 maio 2016.

NUNES, Carla. Grupo de jovens fixa placas sugerindo que joinvilenses caminhem e pedalem pela cidade. Disponível em: <http://ndonline.com.br/joinville/noticias/172036coletivo-Idquo-diverte-inverte-rdquo-faz-intervencao-em-joinville.html>. Acesso em: 04 maio 2016.

RUSSO, Rodrigo. Projeto espalha mapas com pontos de interesse nos bairros paulistanos. Disponível em: <http://www1.folha.uol.com.br/cotidiano/2016/02/1738840-estudantecria-mapa-para-pedestres.shtml>. Acesso em: 04 maio 2016.

SÃO PAULO NEGÓCIOS. A cidade que mais cresce em competitividade. Disponível em: <http://www.spnegocios.com/pt-br/por-que-sao-paulo/cidade-que-mais-crescecompetitividade> Acesso em: 25 abr. 2015.

SHOOT THE SHIT. Disponível em: <https://www.facebook.com/shoottheshit.cc>. Acesso em: 04 maio 2016.

SHOOT THE SHIT. Disponível em: <https://www.shoottheshit.cc/>. Acesso em: 04 maio 2016.

SHOOT THE SHIT. Que ônibus passa aqui? Disponível em:

<http://www.shoottheshit.cc/qopa>. Acesso em: 04 maio 2016.

STARLING, Bruna; COSTA, João Guilherme da; PINNOW, Sarah. Mercado alternativo para design autoral. Palestra proferida na disciplina de Experiências Profissionais. Joinville - SC, em 27 de maio de 2015.

VIANNA, Maurício; et. al. Design thinking: inovação em negócios. Rio de Janeiro: MJV Press, 2012.

WALK YOUR CITY. Disponível em: <https://walkyourcity.org/>. Acesso em: 04 maio 2016.

WHITE, Jan V. Edição e design. Tradução Luis Reyes Gil. São Paulo: JSN Editora, 2006.

ZOTTIS, Luísa. Os pedestres de hoje são os motoristas de amanhã. Disponível em:

<http://thecityfixbrasil.com/2014/01/13/pedestres-virando-motoristas/>. Acesso em: 04 maio 2016. 